\title{
Effectiveness of Active Release Technique Versus Myofascial Release in Patients with Trapezitis - Mini-Review
}

\section{Manashi Dey ${ }^{1 *}$ and Shilpi Pal'}

${ }^{1}$ Course Coordinator, Vydehi Institute of Physiotherapy, Vydehi Institute of Medical Sciences and Research Centre, Bengaluru, India

${ }^{2}$ Assistant Professor, Vydehi Institute of Physiotherapy, Vydehi Institute of Medical Sciences and Research Centre, Bengaluru, India

*Corresponding Author: Manashi Dey, Course Coordinator, Vydehi Institute of Physiotherapy, Vydehi Institute of Medical Sciences and Research Centre, Bengaluru, India.

DOI: 10.31080/ASOR.2022.05.0425
Received: February 11, 2022

Published: February 18, 2022

(C) All rights are reserved by Manashi Dey and Shilpi Pal

\section{Abstract}

Neck is a very common region for the cause of the neck pain due to upper trapezius muscle. Majority of people for example about $2 / 3^{\text {rd }}$ of people experience this neck pain at some points of time in their lives. Prevalence is highest in mid age and women are more commonly affected than the men category. In different studies, neck pain prevalence varies widely with a mean point prevalence of $13 \%$ (range 5.9\% - 38.7\%) and for mean lifetime prevalence of 50\% (range 14.2\% - 71.0\%). Prolonged constrained work position with ley neck or neck-forward bending may imply a risk factor for poor ergonomic habit. Maintaining poor posture for long period of time or sitting in chair in bad posture results in muscle fatigue/fatigues, discomfort or sudden pain eruption. Even-though, if there is no alternation in soft tissues structurally; more significantly prolonged exposure to high static muscle and joint may eventually leads to pathological changes and further leading to permanent disability.

This study helps us to identify the effectiveness of the two techniques i.e. Myofascial Release and Active Release therapy/techniques.

Active Release Therapy (ART) and Myofascial Release (MFR) are soft tissue manipulation techniques practiced by physiotherapists for reducing muscle spasm and pain.

Keywords: Musculoskeletal Condition; Neck Pain; Myofascial Release; Active Release Technique; Trapezitis; Pain

\section{Abbreviations}

MFR: Myo-fascial Release; ART: Active Release Technique

\section{Introduction}

Trapezitis is an inflammation of trapezius muscle (flat triangular shaped muscle) which involve myofascial pain syndrome that can be commonly encountered in clinical practice [1,2].
Pain in trapezius or trapezitis occurs when person does neck extension. This occurs when we sit in faulty posture while watching $\mathrm{TV}$, during walking or prolonged use of the phone/mobile etc. This trapezius pain is present even during rest and is usually aggravated by activity or certain neck position [3].

Neck pain is very common in upper trapezius muscle. About two-thirds of the people experience neck pain at some point of time 
in their lives. In middle age, prevalence is highest and women are more affected than men $[4,5]$.

Neck pain prevalence varies widely on different research studies with a mean point prevalence of $13 \%$ (range $5.9 \%-38.7 \%$ ) and with mean lifetime prevalence of 50\% (range 14.2\% - 71.0\%) [3].

Myofascial Release (MFR) is a soft tissue mobilization technique of Physical-therapy, used to treat MPS (myofascial pain syndrome). It can also be defined as the facilitation of mechanical, neural and psychophysiological adaptive potential as interfaced via myofascial system [6,7]. Mr. Robert Ward, an Osteopath, attributed in coining the term MFR in 1960s. The MFR therapy basically involves lowload, long-duration mechanical forces (specifically) to manipulate the myofascial complex; this further intends towards to restore optimal length, decrease pain and functional improvement $[4,6]$.

Active Release Technique/s is/are used for the recovery of soft tissue function that involves the scar tissue removal. It is a Manual Therapy approach that relieves the tissue tension via the removal of adhesions/fibrosis that can eventually develop in the tissues as a result of the overload from the repetitive usage. That can further cause pain, stiffness, muscle weakness, or abnormal sensations that may include muscles, fascia, and soft tissue mechanical dysfunction [8].

\section{Materials and Methods}

\section{- Study design: Mini Review.}

- Databases: Pub med, PEDro and Google Scholar.

\section{Inclusion criteria}

Full text English language articles of studies in patients with trapezius neck pain. Only intervention studies (such as case reports, Non-RCTs, Quasi RCTs, RCTs) or reviews of intervention studies will be considered onwards from 2014 up-to 2020.

\section{Exclusion criteria}

Studies involving other variants of Psychological problems, herniated disc, cervical radiculopathy, vertigo or any other cervical instability and other degenerative disorder.

\section{Results and Discussion}

The search yields 25 articles out of which 16 articles were included in the review according to the predetermined criteria. Most of the study was done on active release technique and myofascial release with hot pack, foam roller or with roller massage in different muscles [9].

A major aspect of trapezitis or neck pain is deficient muscle relaxation leading to bad posture and limited ROM. Bad posture and work habits such as - prolonged constrained work position with ley neck or neck flexion implies a risk factor. Maintaining bad posture for long periods of time can result in fatigue in muscles, pain or discomfort or pain. Even-though, if there is no alternation in soft tissues structurally; more significantly prolonged exposure to high static muscle and joint may eventually leads to pathological changes and further leading to permanent disability.

Trapezitis or neck pain can happen by keeping the neck in forward position for too-long or talking over the phone by using shoulder to hold the phone near to the ear or in-between ear and one shoulder, sitting in a chair or a stool without proper back support or armrests or stopping in chair, carrying heavy backpacks, or ladies bag on one shoulder etc.

Mechanical dysfunction of the cervical joint can be from abnormal head posture, leading to pain, soft tissue fibrosis, adaptive shortening, loss of flexibility, and mechanical deformation reflects the condition of hypo-mobility, where there is no movement inside the normal joint capsule.

When mechanical dysfunction is present in vertebra, manual therapy is typically performed, and can be an effective method of relieving neck pain related to such dysfunction.

The Review therefore shows that usage of different physiotherapy interventions targeting different aspects of neck pain.

Hence, it clearly states that the results are mixed. Few articles also show that Myofascial release was superior to other treatment techniques, whereas rest showed that the other treatment techniques were equally effective for treating the neck condition/s.

Since few articles only had a pre and post-treatment measurement with no follow-up. To say about the long-term effects would be little impossible.

Thus, it indicates that more research is required or should be 
carried out to find out which is more effective for neck condition either Myofasical release or Active release technique.

To know more significantly which one has more positive approach or response in terms of pain, range of motion and muscle spasm, further need is there to conduct the research.

\section{Conclusion}

On the basis of review of literature, it can be concluded that although, both Myofascial release and Active release technique/s have been found to be effective in reducing pain, disability and increasing the range of motion. Hence, Myofascial release and Active release technique both are effective therapeutic option in terms of treatment of active myofascial trigger point.

\section{Author Contributions}

Manashi Dey and Shilpi Pal contributed to the editing of the manuscript. All authors contributed to the article and approved the submitted version.

\section{Conflict of Interest}

The authors declare that the research was conducted in the absence of any commercial or financial relationships that could be construed as a potential.

\section{Bibliography}

1. Khare D and Pathak R. "Effectiveness of elastic resistance band exercises versus conventional exercises on cases of trapezitis: A comparative study". International Journal of Orthopaedics 4.1 (2018): 174-187.

2. G Noussios. "The Variational Anatomy of the Trapezius Muscle: A Review of the Literature". The Internet Journal of Human Anatomy 3 (2014).

3. Genebra CVDS., et al. "Prevalence and factors associated with neck pain: a population-based study". Brazilian Journal of Physical Therapy (2017).

4. El-hafez H M., et al. "Instrument-assisted soft tissue mobilisations versus stripping massage for upper trapezius myofascial trigger points". Journal of Taibah University Medical Sciences 15.2 (2020): 87-93.

5. Ester Cerezo-Téllez and María Torres-Lacomba. "Prevalence of Myofascial Pain Syndrome in Chronic Non-Specific Neck Pain: A Population-Based Cross-Sectional Descriptive Study". Pain Medicine 17.12 (2016): 2369-2377.
6. Mishra D., et al. "Comparative Study of Active Release Technique and Myofascial Release Technique in Treatment of Patients with Upper Trapezius Spasm". Journal of Clinical and Diagnostic Research 12.11 (2018).

7. Pawaria Sonia and Sheetal Kalra. "Comparing effectiveness of myofascial release and muscle stretching on pain, disability and cervical range of motion in patients with trapezius myofascial trigger points". Indian Journal of Health Sciences and Care 2.1 (2015): 8-13.

8. Jun Ho Kim., et al. "Effects of the active release technique on pain and range of motion of patients with chronic neck pain". Journal of Physical Therapy Science 27.8 (2015): 2461-2464.

9. Scott W Cheatham., et al. "The effects of self-myofascial release using a foam roll or roller massager on joint range of motion, muscle recovery, and performance: a systematic review". International Journal of Sports Physical Therapy 10.6 (2015): 827-838.

\section{Assets from publication with us}

- Prompt Acknowledgement after receiving the article

- Thorough Double blinded peer review

- Rapid Publication

- Issue of Publication Certificate

- High visibility of your Published work

Website: www.actascientific.com/

Submit Article: www.actascientific.com/submission.php

Email us: editor@actascientific.com

Contact us: +919182824667 